\title{
Wave for Independence
}

\author{
Su Kyoung An \& Cassandra Wentela, Central Michigan University
}

Keywords: Uprising, Declaration of Independence, digital printing, laser cutting

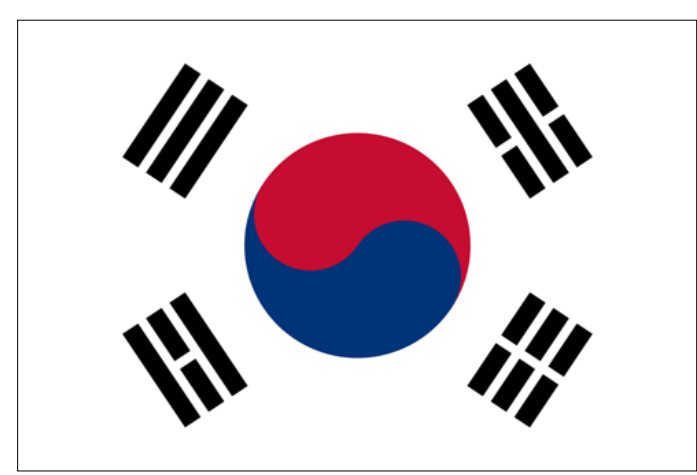

Figure 1. Korean Flag

The purpose of this design was to publicize an official Korean flag, which was established with symbolic meanings and remarkably used in the Korean independence movement in 1919 , called March $1^{\text {st }}$ Movement. The design shows the origin and meaning of the March $1^{\text {st }}$ Movement and Korea's independence from Japanese colonial rule by inspiring Korean flag into the design that was created. 2019 is the $100^{\text {th }}$ anniversary of the March $1^{\text {st }}$ Movement, and it should be a very important year to remember Korea's independence once again (Kim, 2019). Designers began to research the Korean's nonviolent and democratic uprising during the March $1^{\text {st }}$ Movement in 1919 and began ideation on how to apply Korean flag (Figure 1) and Declaration of Korean Independence into the design to commemorate 100 years of the movement.

The March $1^{\text {st }}$ Movement essentially represents people uniting to resist Japan's control with students and people gathering all across the country in order to stand up for their freedom (Shin, 2018). During the time of this upheaval, 1919, about 2 million Koreans participated in about 1500 demonstrations in order to make a change for a better future (March First Movement, 2014). These demonstrations showed how strongly Koreans were determined to regain national independence and how they were united as one.

Viewing imagery and artworks from this movement, designers found many Korean who participated in the uproar wore the traditional white overcoat and waved the Korean flag because the Korean flag was a weapon of symbolic significance. The sense of hope, the Korean flag provided for the March $1^{\text {st }}$ Movement, was desired to capture in order to give an accurate representation of this monumental moment in Korea's history. Thus, the Korean flag is where the aesthetic inspiration of this wearable garment came from.

The main colors of this garment were white (meaning peace), red (meaning morning or eastern brightness), and blue (meaning evening or western shadow) with accents of black (Nelson, 2000). A strapless, princess seam, and mermaid style dress was draped by using muslin on a size six dress form. Circle openings along the side waist were left open to apply black straps to have more of an emphasis,

Published under a Creative Commons Attribution License (https://creativecommons.org/licenses/by/4.0/), which permits unrestricted use, distribution, and reproduction in any medium, provided the original work is properly cited.

ITAA Proceedings, \#76 - https: / /itaaonline.org 
which were derived from the black trigrams in each corner of the Korean flag. Among four black trigrams, only two trigrams, $\mathrm{Ri}$ (meaning water) and Gam (meaning fire), were placed into the front and back waist of the dress. In the bottom of the dress, a full circle ruffle was inspired by the center symbol, which is called "TaeGuek," of the Korean flag and mimicked the symbol. The short bolero jacket was flat-patterned with the slight bell sleeves. The 3" wide mandarin collar was attached to the wide scoop neckline.

Final pattern pieces were digitized into Modaris software and converted DXF files to open them into Adobe Illustrator. The full circle ruffle of the dress in the bottom includes both Korean and English versions of the Declaration of Korean Independence, which was announced that Korea would no longer tolerate Japanese colonial rule on March $1^{\text {st }}, 1919$ in public (Kim, 2019). In Adobe Illustrator, the whole declaration of Korean Independence was digitally printed in the red portion of ruffle (Korean version) and the blue portion of ruffle (English version). The 1" black outlines were added outside of the circle and in the middle line in order to stand out the shape of "TaeGuek" (Figure 2).

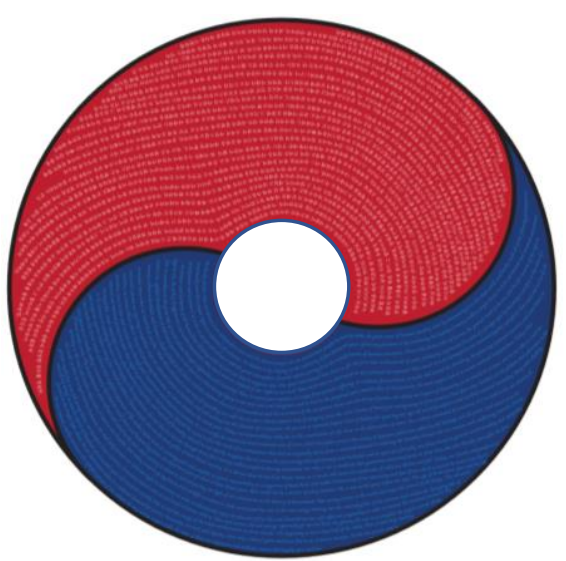

Figure 2. Full Circle Ruffle

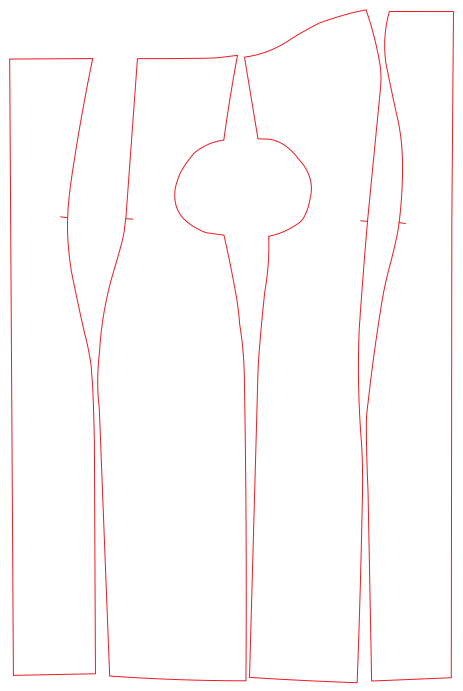

Figure 3. Pattern File for Laser Cutting

For this design project, the designers used the Universal Laser ILS 12.150D model to cut out the pattern piece onto the soft velvet for dress and polyester organza for bolero jacket. To find out the appropriate setting for each fabric, the designers practiced several times with different setting of power, speed, and PPI of laser cutter to prevent each fabric from fraying and raveling after cutting all pattern pieces by laser cutting technique. In Adobe Illustrator, all digitized patterns were opened in RGB color mode and the designers changed the black pattern outlines to red (R:255, G:0, B:0) outlines with stroke weight of $0.001 \mathrm{pt}$ (Figure 3).

Published under a Creative Commons Attribution License (https://creativecommons.org/licenses/by/4.0/), which permits unrestricted use, distribution, and reproduction in any medium, provided the original work is properly cited. 
The dress was constructed to contour to the curves of the body. One digitally printed full circle ruffle, which was laser-cut, was placed at the knee level of the princess line dress and an invisible zipper was located at center back. A facing was created to finish the bust line of the dress onto the soft velvet. The bolero jacket was finished with a French seam technique to clean the inside with black polyester organza. One black knot button was placed at center back of bolero jacket for closure.

The Wave for Independence is a wearable garment to honor the origin and meaning of the March $1^{\text {st }}$ Movement, which fought peacefully for the nation's independence by using the Korean flag symbolically. The designers successfully interpreted the symbolic Korean flag and applied features of the flag and Declaration of Korean Independence into fashion through digital printing and laser cut techniques.

\section{References:}

Kim, R. (2019). Korea's March First Movement of 1919, 100 years later. Retrieved from https://americanpyongyang.com/2019/03/01/koreas-march-first-movement-of-1919-100-yearslater/

March first movement. (2014). Retrieved from http://www.newworldencyclopedia.org/entry/March_First Movement

Nelson, P. (2000). History of the South Korean Flag. Retrieved https://web.archive.org/web/20170326052449/http://www.christusrex.org/www3/fotw/flags/kr_hi $\underline{\text { st.html }}$

Shin, M. (2018). Korean National Identity under Japanese Colonial Rule [electronic resource]:

Yi Gwangsu and the March First Movement Of 1919. (Routledge studies in the modern history of Asia). Milton, UK: Routledge. 


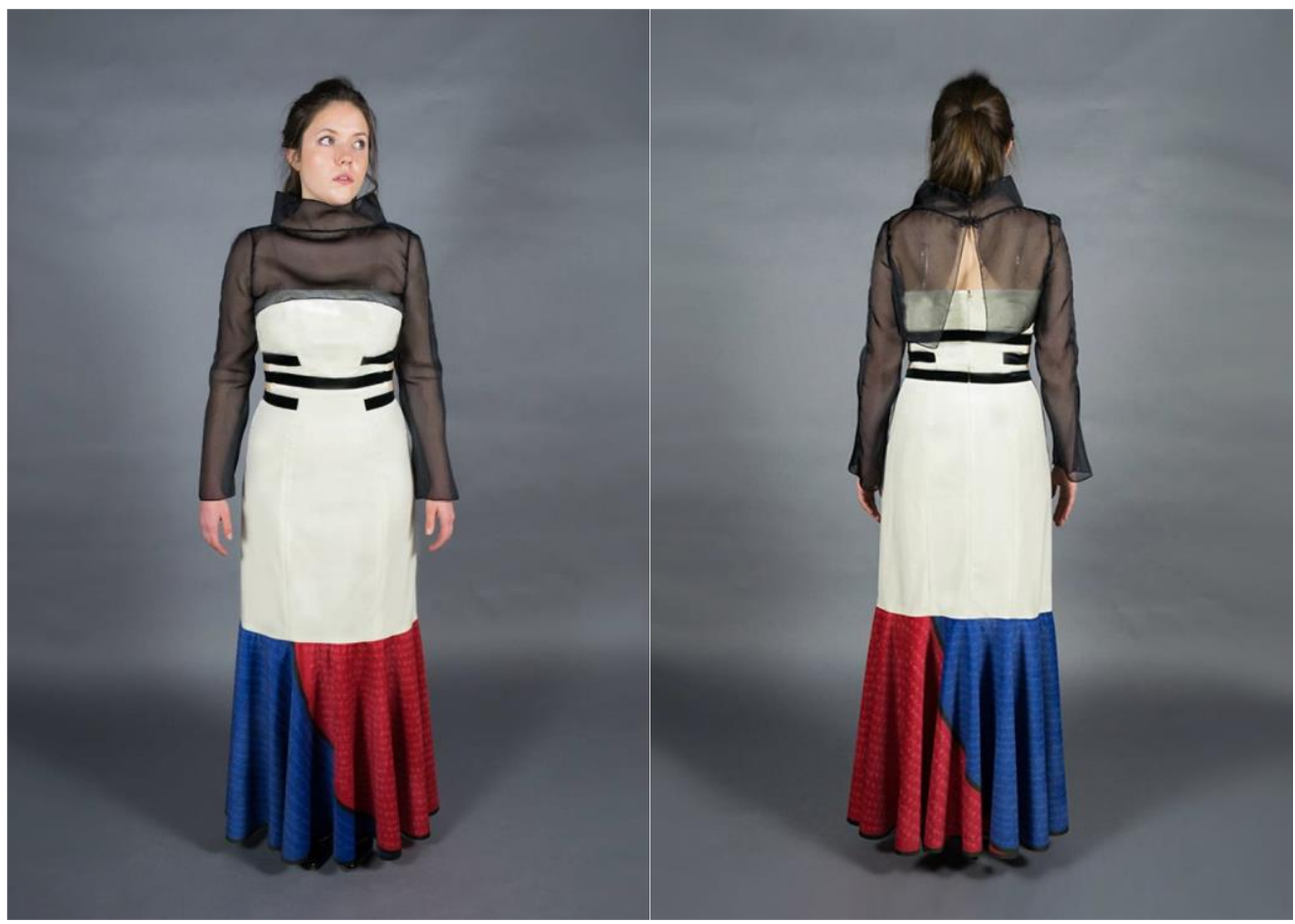

Image A. Front View

Image B. Back View

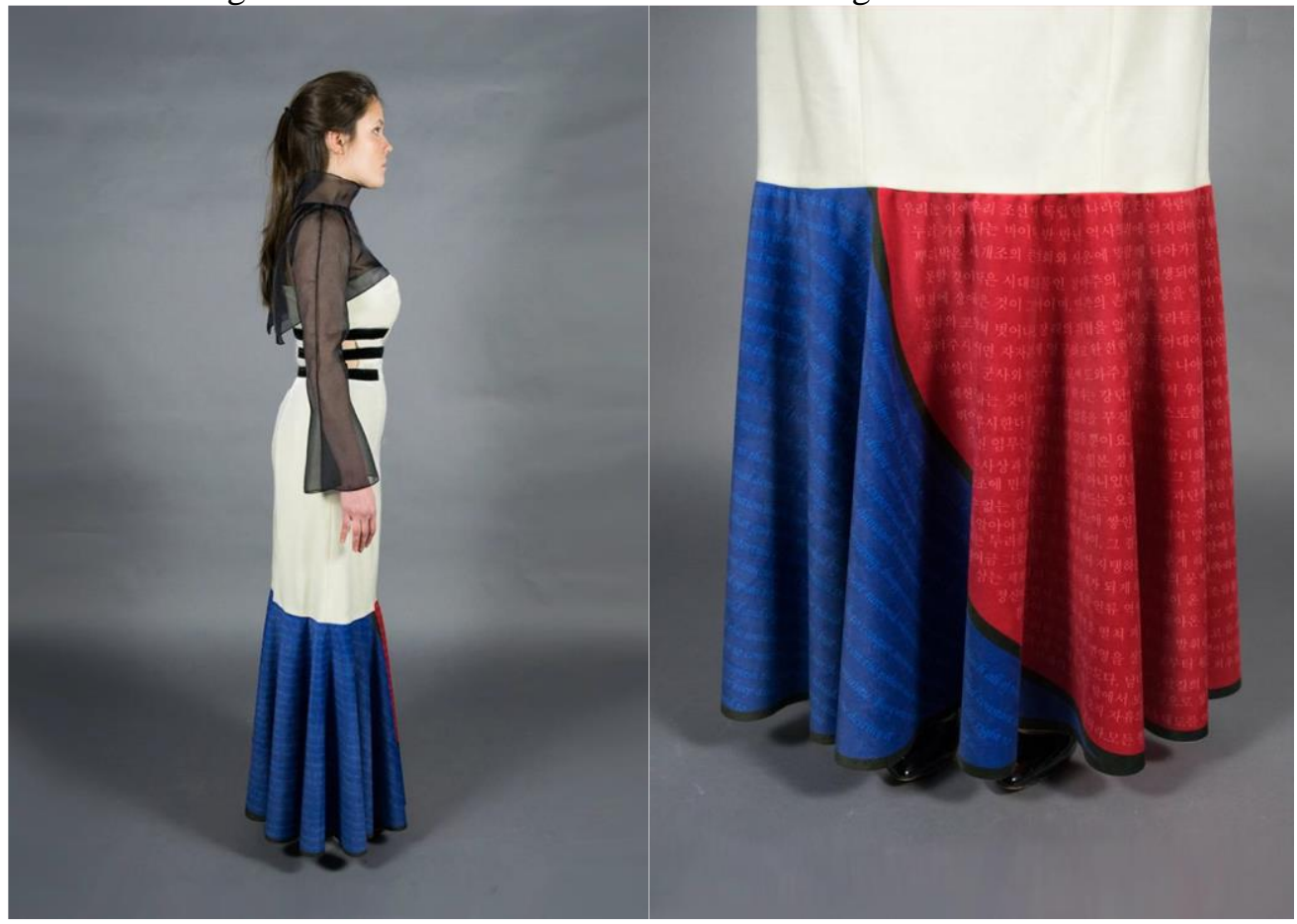

Image C. Side View

Image D. Detail View

Page 4 of 4

Published under a Creative Commons Attribution License (https://creativecommons.org/licenses/by/4.0/), which permits unrestricted use, distribution, and reproduction in any medium, provided the original work is properly cited.

ITAA Proceedings, \#76 - https://itaaonline.org 